\title{
PENGUKURAN PERFORMA DIGITAL DISTRIBUTION CHANNEL TERHADAP KEPUTUSAN PEMBELIAN HOSTEL PADA PINISI BACKPACKER DENGAN MULTINOMIAL LOGISTIC REGRESSION
}

\author{
Aditia Sovia Pramudita ${ }^{1}$ \\ ${ }^{1}$ Program Studi Logistik Bisnis, Politeknik Pos Indonesia \\ Email: aditiasovia@poltekpos.ac.id
}

\begin{abstract}
The growth of the tourism industry in Indonesia is growing rapidly. This growth has an impact on the growth of inn needs in Indonesia. Pinisi Backpacker as one of the inns with the hostel concept has a role in the growth of this industry. The role of online travel agents in this industry also has a significant role in inn`s sales throughout the world. However, the use of online travel agents themselves is not without risks. Cooperation with online travel agents has the potential for innkeepers to experience opportunity lost. This shows that inn owners need to assess the performance of each online travel agent as their partner. Based on the results of the study it was found that all of the online travel agent has positive and significant impact except Traveloka and Expedia. Consumer purchasing decisions at Pinisi Backpacker hostels are influenced by the selection of online travel agents by their customers. From all online travel agents used, it can be concluded that there are three grade online travel agents for Pinisi Backpackers, namely grade 1, namely Booking.com, Agoda, and Hostelworld; grade 2 is Klikhotel and strategy; and the last is to release online travel agent cooperation with Traveloka and Expedia.
\end{abstract}

Keywords: Hostel, Online Travel Agent, Digital Distribution Channel, Multinomial Logistic Regression

\begin{abstract}
Abstrak
Pertumbuhan industri pariwisata di Indonesia berkembang dengan pesat. Pertumbuhan tersebut berdampak pada pertumbuhan kebutuhan penginapan di Indonesia. Pinisi Backpacker sebagai salah satu penginapan dengan konsep hostel memiliki peran dalam pertumbuhan industri ini. Peran online travel agent pada industri ini pun memiliki peran yang signifikan terhadap penjualan penginapan di seluruh dunia. Namun demikian penggunaan online travel agent sendiri bukannya tanpa risiko. Kerjasama dengan online travel agent memiliki potensi bagi pemilik penginapan untuk mengalami opportunity lost. Hal tersebut menunjukan bahwa pemilik penginapan perlu untuk mengkaji performa masing-masing online travel agent sebagai partnernya. Berdasarkan hasil penelitian ditemukan bahwa seluruh OTA memberikan efek yang positif terhadap keputusan pembelian hostel kecuali Traveloka dan Expedia. Keputusan pembelian konsumen di hostel Pinisi Backpacker dipengaruhi oleh pemilihan online travel agent oleh para konsumennya. Dari seluruh online travel agent yang digunakan dapat disimpulkan terdapat tiga grade online travel agent bagi Pinisi Backpacker yaitu grade 1 adalah Booking.com, Agoda, dan Hostelworld; grade 2 adalah Klikhotel dan pegipegi; dan yang terakhir adalah melepas kerjasama online travel agent dengan Traveloka dan Expedia.
\end{abstract}

Kata Kunci: Hostel, Online Travel Agent, Saluran Distribusi Digital, Regresi Logistik Multinomial

\section{PENDAHULUAN}

Pariwisata di Indonesia merupakan salah satu industri yang diprediksi menjadi salah satu penopang ekonomi negara. Hal tersebut pun ditunjukan dengan pertumbuhan investasi pada bidang pariwisata dimana di Indonesia sendiri terdapat dua sektor yang berpotensi tumbuh pesat secara investasinya di Indonesia yaitu sektor pariwisata dan e-commerce (Badan Koordinasi Penanaman Modal, 2018). Sektor pariwisata sendiri pada tahun 2017 telah mampu mencetak nilai Produk Dometik Bruto sebesar 15\% (Badan Pusat Statisik, 2018). Selain itu, industri pariwisata sendiri telah mampu mendatangkan 20 juta kunjungan wisatawan mancanegara dan 275 juta kunjungan wisatawan nusantara (Liputan 6, 2018). 
Bandung merupakan salah satu kota di Indonesia yang menjadi tujuan pariwisata baik domestik maupun mancanegara. Hal tersebut ditunjukan dengan pedulinya pemerintah Kota Bandung untuk mengembangkan industri pariwisata. Infrastruktur pendukung pariwisata di kota Bandung dijadikan prioritas agar dapat menggali potensi pariwisata yang ada di kota tersebut. Hal tersebut berdampak pada besarnya minat wisatawan untuk mengunjungi Kota Bandung sebagai tujuan wisata mereka. Di bawah ini merupakan data jumlah pertumbuhan wisatawan di Kota Bandung tahun 2011-2016.

Tabel 1 Jumlah Wisatawan di Kota Bandung

\begin{tabular}{|c|c|c|c|}
\hline \multirow{2}{*}{ Tahun } & \multicolumn{2}{|c|}{ Wisatawan } & \multirow{2}{*}{ Jumlah } \\
\cline { 2 - 3 } & Mancanegara & Domestik & \\
\hline 2011 & 225585 & 6487239 & 6712824 \\
\hline 2012 & 176855 & 5080584 & 5257439 \\
\hline 2013 & 176432 & 5388292 & 5564724 \\
\hline 2014 & 180143 & 5627421 & 5807564 \\
\hline 2015 & 183932 & 5877162 & 6061094 \\
\hline 2016 & 173036 & 4827589 & 5000625 \\
\hline
\end{tabular}

Sumber: (Badan Pusat Statisik, 2018)

Berdasarkan indikasi pertumbuhan pada Tabel 1, penginapan sebagai salah satu pendukung sektor pariwisata merupakan salah satu faktor yang penting. Kota Bandung sendiri telah memiliki banyak hotel dengan berbagai kelas. Di bawah ini merupakan data jumlah hotel yang ada di kota Bandung pada tahun 2016.

\begin{tabular}{l} 
Tabel 2 Jumlah Hotel di Bandung Tahun 2016 Berdasarkan Kelasnya \\
$\qquad$\begin{tabular}{|c|c|c|}
\hline Klasifikasi & Jumlah & Kamar \\
\hline Hotel Bintang 5 & 9 & 1870 \\
\hline Hotel Bintang 4 & 32 & 3651 \\
\hline Hotel Bintang 3 & 42 & 3507 \\
\hline Hotel Bintang 2 & 25 & 1500 \\
\hline Hotel Bintang 1 & 10 & 382 \\
\hline Non Bintang & 218 & 6041 \\
\hline
\end{tabular} \\
\hline
\end{tabular}

Jumlah penginapan di Bandung sendiri terus meningkat seiring dengan berjalannya waktu. Hal tersebut membuat kekhawatiran pemilik penginapan terkait dengan tingkat okupansi penginapan mereka. Selama tahun 2017 sendiri, tingkat okupansi keterisian penginapan berada pada level 40-50\% pada hari biasa dan mampu mencapai 80\% pada hari libur (Pikiran Rakyat, 2018). Berdasarkan hal tersebut industri penginapan ini masih dapat dikategorikan potensial.

Tumbuhnya industri penginapan sendiri didukung dengan banyaknya online travel agent sebagai salah satu fungsi dari digital distribution channel yang dimiliki oleh masing-masing penginapan. Penggunaan digital distribution channel merupakan sesuatu yang penting bahkan tidak hanya pada industri penginapan saja. Pertumbuhan dan penetrasi Internet and Communication Technology (ICT) di dunia memang sangat tinggi. Perubahan penjualan dalam bentuk digital atau melalui saluran digital menjadi sangat penting dikarenakan memiliki konsumen masa depan memiliki kecenderungan untuk mengakses informasi melalui media digital (Pramudita, Yanuar, \& Hilman, 2019). Hal tersebut menjadi indikasi bahwa pentingnya media digital dalam penyebaran informasi khususnya dalam industri penginapan.

Penggunaan media digital pada industri penginapan sendiri secara umum dilakukan untuk membantu penjualan kamar. Selain melalui personal website, penginapan pun menggunakan online travel agent (OTA) sebagai bantuan untuk penyebaran penjualan kamarnya (Li-ming \& Wai, 2013). Pentingnya 
peran OTA dalam penjualan pun diperkuat dengan hasil survey yang menunjukan bahwa $71,44 \%$ masyarakat pernah menggunakan OTA untuk keperluan reservasi hotel/ penginapan dalam 6 bulan terakhir pada tahun 2018 (Daily Social Id, 2018). Performa OTA pada masing-masing penginapan pun memiliki performa yang berbeda-beda. Pengukuran performa OTA sendiri menjadi penting agar pemiliki penginapan tidak perlu untuk membagi kamar mereka pada banyak OTA dikarenakan penginapan dapat mengalami opportunity lost.

Pinisi Backpacker merupakan hostel yang memiliki fokus pendistribusian melalui personal website dan OTA (Pramudita, 2018). Hal tersebut membuat Pinisi Backpacker menjadi objek yang tepat untuk dapat melakukan evaluasi performa OTA yang dtelah digunakan. Selain itu, hingga saat ini pun pengunjung Pinisi Backpacker sebanyak 50\%-nya merupakan wisatawan macanegara dimana dapat diasumsikan bahwa mereka menggunakan OTA untuk dapat membeli kamar di Pinisi Backpacker. Selain itu, opportunity lost sendiri dirasakan oleh Pinisi Backpacker dikarenakan kamar yang sudah di-listing di OTA tidak boleh dijual kepada orang lain sebagai bentuk komitmen terhadap OTA yang diajak bekerja sama.

\section{METODE PENELITIAN \\ Saluran Distribusi}

Saluran distribusi adalah serangkaian organisasi yang saling tergantung dan terlibat dalam proses untuk menjadikan suatu barang atau jasa siap untuk digunakan atau dikonsumsi (Kotler \& Keller, 2012). Sistem distribusi dapat dibedakan dalam dua jenis, yaitu sistem distribusi langsung dan sistem distribusi tidak langsung. Sistem distribusi langsung mendistribusikan barang secara langsung dari produsen ke konsumen. Saluran distribusi memiliki fungsi sebagai perantara antara produsen dan konsumen sehingga fungsinya sebagai market enabler. Perantara tersebut dapat digolongkan kedalam dua golongan yaitu pedagang perantara dan agen perantara. Perbedaannya terletak pada aspek pemilikan serta proses negoisasi dalam pemindahan produk yang disalurkan tersebut.

1. Pedagang perantara

Pedagang perantara (merchant middleman) ini bertanggung jawab terhadap pemilikan semua barang yang dipasarkannya atau dengan kata lain pedagang mempunyai hak atas kepemilikan barang.

2. Agen Perantara

Agen perantara (Agent middleman) merupakan party yang tidak mempunyai hak milik atas semua barang yang mereka tangani sehingga perannya benar-benar hanya sebagai middleman.

Agar suatu kegiatan penyaluran dapat berjalan sesuai dengan fungsinya, maka setiap pihak harus dapat melakukan tugasnya dengan baik khususnya menjalankan fungsi mereka sebagai saluran distribusi (Kotler, 2007). Adapun fungsi dari saluran distribusi adalah:

1. Penelitian, yaitu melakukan pengumpulan informasi penting untuk perencanaan dan melancarkan pertukaran.

2. Promosi, yaitu pengembangan dan penyebaran informasi yang persuasive mengenai penawaran.

3. Kontak, yaitu melakukan pencarian dan menjalin hubungan dengan pembeli.

4. Penyelarasan, yaitu mempertemukan penawaran yang sesuai dengan permintaan pembeli termasuk kegiatan seperti pengolahan, penilaian dan pengemasan.

5. Negoisasi, yaitu melakukan usaha untuk mencapai persetujuan akhir mengenai harga dan lainlain sehubungan dengan penawaran sehingga pemindahan pemilikan atau penguasaan bias dilaksanakan.

6. Distribusi fisik, yaitu penyediaan sarana transportasi dan penyimpanan barang.

7. Pembiayaan, yaitu penyediaan permintaan dan pembiayaan dana untuk menutup biaya dari saluran pemasaran tersebut.

8. Pengambilan resiko, yaitu melakukan perkiraan mengenai resiko sehubungan dengan pelaksanaan pekerjaan saluran tersebut. 
Kelima tugas pertama membantu pelaksanaan transaksi dan tiga yang terakhir membantu penyelesaian transaksi. Semua tugas diatas mempunyai tiga persamaan, yaitu menggunakan sumber daya yang langka, dilaksanakan dengan menggunakan keahlian yang khusus, dan bisa dialih-alihkan diantara penyalur. Apabila perusahaan/produsen menjalankan seluruh tugas diatas, maka biaya akan membengkak dan akibatnya harga akan menjadi lebih tinggi (Ratnawati, 2015).

\section{Keputusan Pembelian}

Kehidupan manusia tidak lepas dari melakukan jual beli. Sebelum melakukan pembelian, seseorang biasanya akan melakukan keputusan pembelian terlebih dahulu terhadap suatu produk. Keputusan pembelian merupakan kegiatan individu yang secara langsung terlibat dalam pengambilan keputusan untuk melakukan pembelian terhadap produk yang ditawarkan oleh penjual. Pengertian keputusan pembelian adalah tahap dalam proses pengambilan keputusan pembeli di mana konsumen benar-benar membeli (Kotler, 2001).

Pengambilan keputusan merupakan suatu kegiatan individu yang secara langsung terlibat dalam mendapatkan dan mempergunakan barang yang ditawarkan. Definisi lain keputusan pembelian adalah keputusan pembeli tentang merek mana yang dibeli. Konsumen dapat membentuk niat untuk membeli merek yang paling disukai. Keputusan pembelian merupakan suatu proses pengambilan keputusan akan pembelian yang mencakup penentuan apa yang akan dibeli atau tidak melakukan pembelian (Kotler \& Amstrong, 2008).

Keputusan konsumen timbul karena adanya penilaian objektif atau karena dorongan emosi. Keputusan untuk bertindak adalah hasil dari serangkaian aktivitas dan rangsangan mental emosional. Proses untuk menganalisa, merasakan dan memutuskan, pada dasarnya adalah sama seperti seorang individu dalam memecahkan banyak permasalahannya. Adapun tahapan keputusan pembelian dapat dilihat pada gambar dibawah ini.

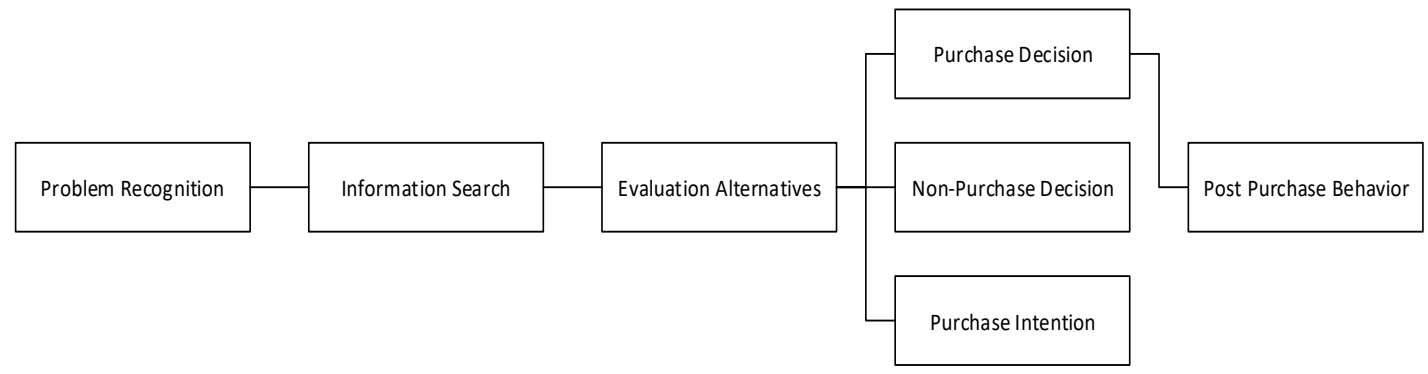

Gambar 1 Tahapan Keputusan Pembelian

Sumber: Kotler \& Keller, 2012

Pada dasarnya pengambilan keputusan konsumen terhadap suatu produk berbeda-beda tergantung pada jenis keputusan pembeliannya. Pembelian yang rumit dan mahal mungkin melibatkan banyak peserta tetapi dalam proses pembelian tertentu. Konsumen harus melewati beberapa tahap, yang dikenal dengan "model tingkat". Model ini menunjukkan bahwa konsumen harus melalui 5 (lima) tahapan - tahapan dalam proses pembelian dalam sebuah produk.

\section{Kerangka Pemikiran}

Pertumbuhan OTA di Indonesia membuat pengusaha perlu untuk mengevaluasi performa masingmasing OTA. Semakin banyaknya OTA yang digunakan oleh penginapan dapat membuat pemilik penginapan mengalami opportunity lost. Penelitian ini memberikan paradigma pengukuran performa OTA dengan menggunakan regresi logistik multinomial. Regresi logistik multinomial ini dilakukan untuk mengukur probability kesuksesan pembelian dari masing-masing OTA yang digunakan terhadap keputusan pembelian konsumen. Populasi penelitian ini adalah pengguna hostel Pinisi Backpacker dalam waktu Januari 2018 hingga Desember 2018. Adapun kerangka pemikiran penelitian ini dapat dilihat pada gambar di bawah ini. 


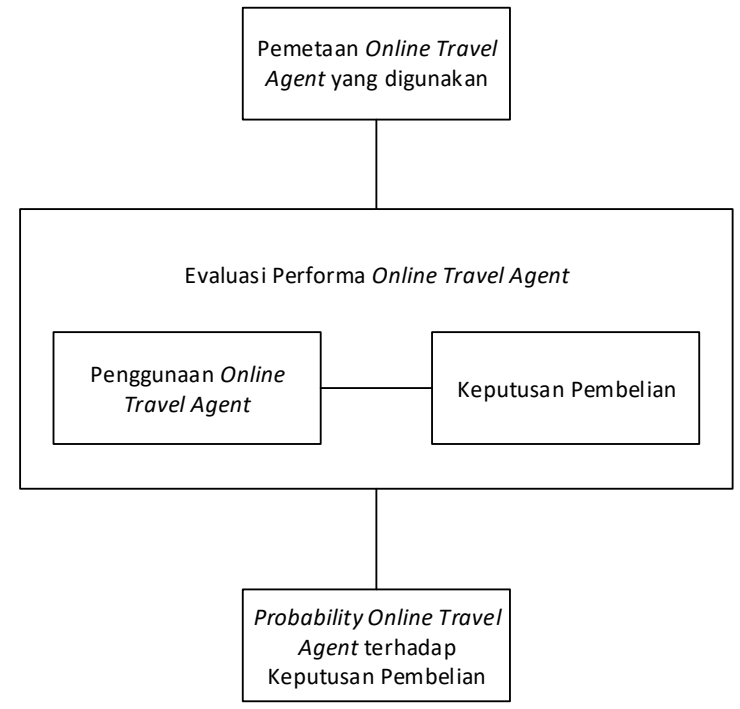

Gambar 2 Kerangka Pemikiran

Hasil dari penelitian ini merupakan rekomendasi OTA terbaik yang seharusnya diprioritaskan oleh Pinisi Backpacker. Prioritas OTA digunakan untuk menghindari terjadinya opportunity lost.

\section{HASIL PENELITIAN DAN PEMBAHASAN}

Pinisi Backpacker membagi penjualan mereka kedalam 8 saluran yaitu personal website Pinisi Backpacker yang berafiliasi dengan klikhotel, Agoda, Traveloka, Booking.com, pegipegi, hostelworld, expedia, dan go show.

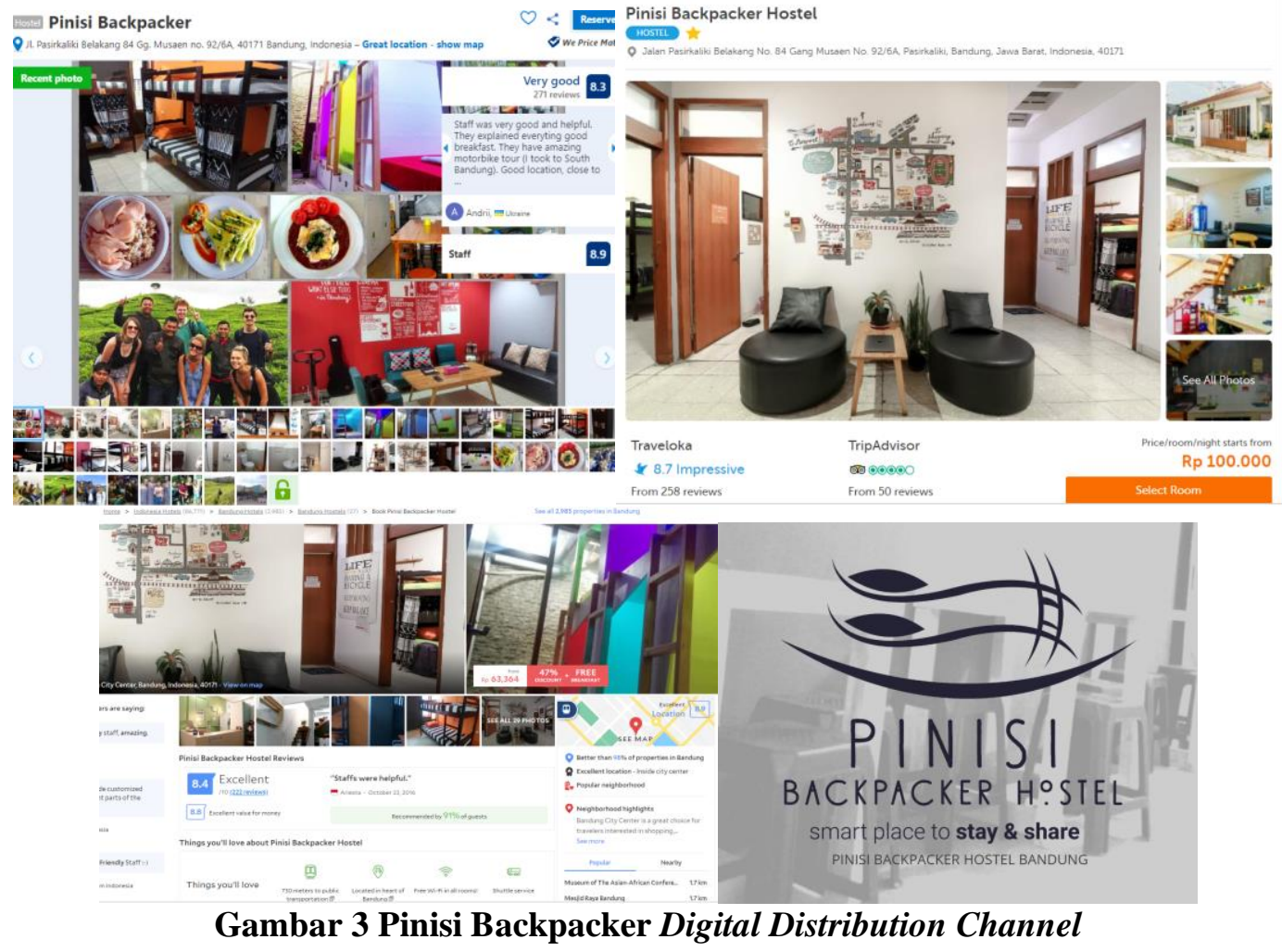

Banyaknya saluran distribusi yang digunakan meningkatkan kemungkinan terjadinya opportunity lost seperti yang telah dijelaskan di awal. Masing-masing saluran distribusi tersebut sebenarnya memiliki pros and cons mereka masing-masing. Namun demikian hal tersebut tidak perlu dibahas lebih jauh 
dikarenakan yang perlu dievaluasi adalah performa masing-masing saluran distribusi khususnya OTA selama tahun 2018.

Pengujian ini menggunakan regreli logistik multinomial untuk dapat melihat pengaruhnya masingmasing OTA terhadap keputusam pembelian hostel di Pinisi Backpacker. Data yang digunakan adalah data pemilihan digital distribution channel dan keputusan pembelian. Adapun hasilnya dapat dilihat di bawah ini.

Tabel 3 Case Processing Summary

\begin{tabular}{|l|l|r|r|}
\hline \multicolumn{2}{|c|}{} & $N$ & $\begin{array}{c}\text { Marginal } \\
\text { Percentage }\end{array}$ \\
\hline \multirow{3}{*}{ Keputusan Pembelian } & Pembelian & 1163 & $95.6 \%$ \\
\cline { 2 - 4 } & Canceled & 54 & $4.4 \%$ \\
\hline Saluran Distribusi & Booking.com & 400 & $32.9 \%$ \\
\cline { 2 - 4 } & Agoda & 289 & $23.7 \%$ \\
\cline { 2 - 4 } & Hostelworld & 205 & $16.8 \%$ \\
\cline { 2 - 4 } & Traveloka & 140 & $11.5 \%$ \\
\cline { 2 - 4 } & Klikhotel & 119 & $9.8 \%$ \\
\cline { 2 - 4 } & pegi-pegi & 52 & $4.3 \%$ \\
\cline { 2 - 4 } & Expedia & 12 & $1.0 \%$ \\
\hline Valid & & 1217 & $100.0 \%$ \\
\hline Missing & & 1217 & \\
\hline Total & & & \\
\hline Subpopulation & & & \\
\hline
\end{tabular}

Dari tabel 3 dapat dilihat bahwa selama penjualan di tahun 2018, 95,6\% penjualan sukses terjadi dan $4,4 \%$ nya mengalami pembatalan. Pembatalan tersebut yang menyebabkan pihak hostel mengalami opportunity lost dikarenakan tidak dapat menjual kamarnya kepada konsumen lainnya. Selain itu, secara frekuensi Booking.com, Hostelworld, dan Traveloka menyumbang proporsi terbesar dalam pemesanan hostel melalui OTA.

Tabel 4 Model Fitting Information

\begin{tabular}{|c|c|c|c|c|}
\hline \multirow{2}{*}{ Model } & $\begin{array}{c}\text { Model Fitting } \\
\text { Criteria }\end{array}$ & \multicolumn{3}{|c|}{ Likelihood Ratio Tests } \\
\cline { 2 - 5 } & $\begin{array}{c}-2 \text { Log } \\
\text { Likelihood }\end{array}$ & Chi-Square & df & Sig. \\
\hline Intercept Only & 37.759 & & & \\
\hline Final & 25.388 & 12.371 & 6 & .054 \\
\hline
\end{tabular}

Signifikansi model yang digunakan menunjukan bahwa variabel independen tidak mempengaruhi secara signifikan karena nilai $p$-value masih lebih besar dari nilai $\alpha=0.05$.

\section{Tabel 5 Koefisien Determinasi}

\begin{tabular}{|l|r|}
\hline Cox and Snell & .010 \\
\hline Nagelkerke & .033 \\
\hline McFadden & .028 \\
\hline
\end{tabular}

Koefisien $\mathrm{R}^{2}$ yang digunakan mengacu kepada nilai Nagelkerke sebesar 0.033 yang memiliki arti bahwa variabel keputusan pembelian dapat dijelaskan oleh variabel digital distribution channel sebesar 3.3\% dan sisanya dipengaruhi faktor lainnya. 
Tabel 6 Estimasi Parameter

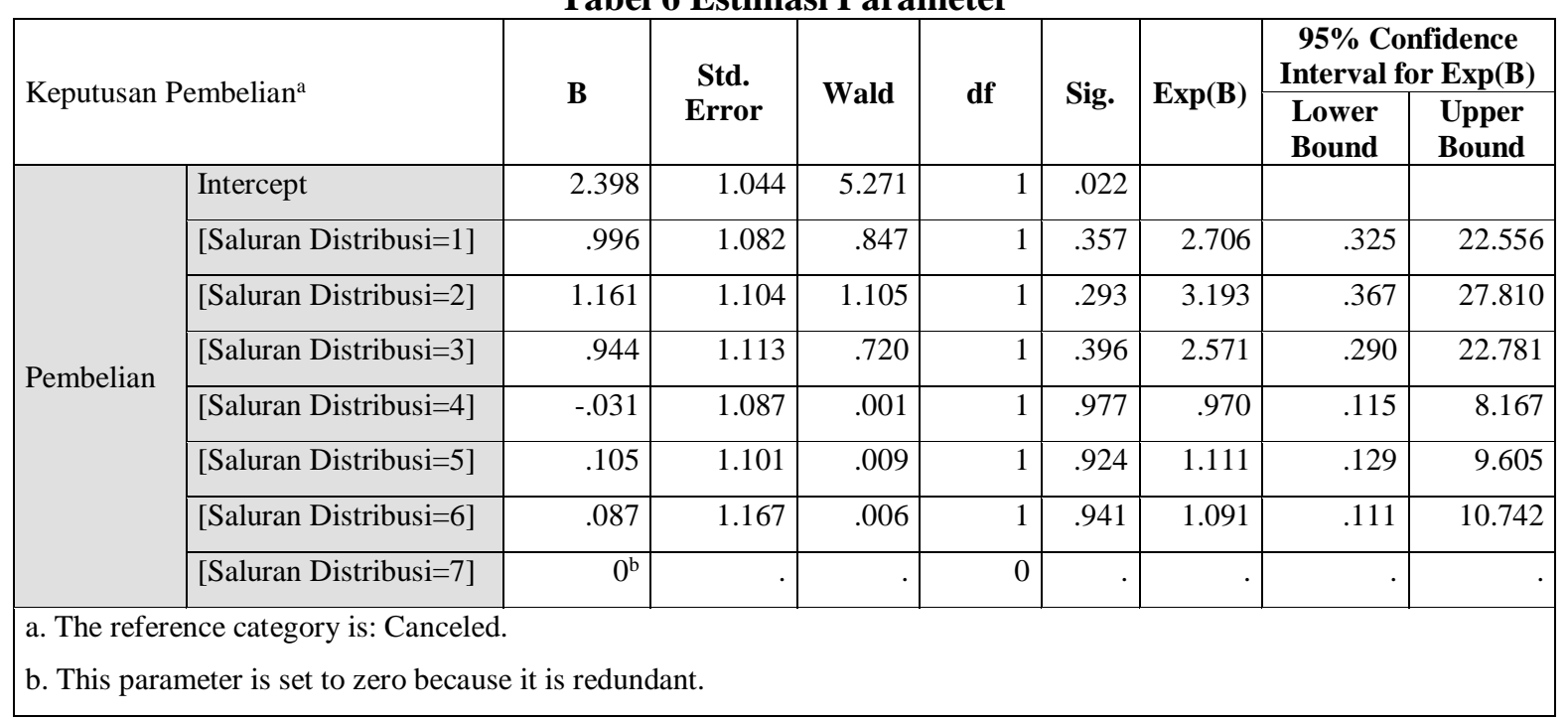

$\begin{array}{ll}\text { Keterangan } & \text { Saluran Distribusi: } \\ 1 & \text { Booking.com } \\ 2 & \text { Agoda } \\ 3 & \text { Hostelworld } \\ 4 & \text { Traveloka } \\ 5 & \text { Klikhotel } \\ 6 & \text { pegipegi } \\ 7 & \text { Expedia }\end{array}$

Secara umum, keputusan pembelian hostel di Pinisi Backpacker melalui OTA dapat diformulasikan dengan $g l(X)=2,398+0,996 X_{1}+1,161 X_{2}+0,944 X_{3}-0,031 X_{4}+0,105 X_{5}+0,087 X_{6}+0,000 X_{7}$, dimana:

$\begin{array}{ll}g l(X) & \text { Keputusan Pembelian } \\ \mathrm{X}_{1} & \text { Booking.com } \\ \mathrm{X}_{2} & \text { Agoda } \\ \mathrm{X}_{3} & \text { Hostelworld } \\ \mathrm{X}_{4} & \text { Traveloka } \\ \mathrm{X}_{5} & \text { Klikhotel } \\ \mathrm{X}_{6} & \text { pegipegi } \\ \mathrm{X}_{7} & \text { Expedia }\end{array}$

Hasil tersebut menunjukan bahwa seluruh OTA memberikan efek yang positif terhadap keputusan pembelian hostel kecuali Traveloka. Selain itu, Expedia pun memberikan efek yang tidak signifikan atau memiliki nilai 0 sehingga tidak memberikan efek terhadap keputusan pembelian. Kedua OTA tersebut merupakan OTA yang perlu untuk dipertimbangkan Pinisi Backpacker untuk tidak digunakan kembali. Terdapat 3 OTA yang memiliki dampak paling besar terhadap kesuksesan pembelian yaitu Booking.com, Agoda, dan Hostelworld. Ketiga OTA tersebut memiliki efek positif dan memiliki nilai eksponensial Beta yang paling tinggi dibandingkan OTA lainnya. Ketiga OTA tersebut masuk menjadi grade 1 sebagai partner OTA. Grade selanjutnya adalah Klikhotel dan pegipegi.

Hasil yang menarik adalah buruknya performa Traveloka terhadap keputusan pembelian konsumen hostel di Pinisi Backpacker. Traveloka sebagai salah satu OTA terbesar di Indonesia diasumsikan memiliki performa yang baik dibandingkan dengan OTA lainnya. Namun pada kenyataannya Traveloka memiliki performa terburuk. Hal tersebut dapat diakibatkan oleh berbagai macam faktor seperti tidak cocoknya segmentasi pengguna Traveloka untuk pengguna hostel khususnya di Pinisi Backpacker. Penemuan tersebut dapat menjadi tema penelitian selanjutnya terkait kecocokan segmentasi Traveloka dengan konsumen hostel. 


\section{KESIMPULAN}

Pinisi Backpacker menggunakan mayoritas saluran distribusinya melalui online travel agent. Penggunaan OTA memiliki risiko terjadinya opportunity lost. Opportunity lost terjadi dikarenakan adanya pembatalan dari konsumen sehingga Pinisi Backpacker tidak dapat menjual kamarnya kepada konsumen lainnya sehingga pada kenyataannya Pinisi Backpacker mengalami kerugian.

Berdasarkan hasil pengukuran dari pemilihan OTA terhadap keputusan pembelian menemukan tiga rekomendasi yaitu membagi OTA menjadi dua grade yaitu grade 1 adalah Booking.com, Agoda, dan Hostelworld; grade 2 adalah Klikhotel dan pegipegi; dan yang terakhir adalah melepas kerjasama OTA dengan Traveloka dan Expedia.

\section{REFERENSI}

Badan Koordinasi Penanaman Modal. (2018). Kepala BKPM: Investor Minati Sektor Pariwisata RI. Retrieved from https://www.bkpm.go.id/id/publikasi/detail/berita/kepala-bkpm-investor-minatisektor-pariwisata-ri

Badan Pusat Statisik. (2018). Bandung Municipality in Figures. Retrieved from https://bandungkota.bps.go.id/publication/download.html?nrbvfeve=YTI3ODJhZTYyMDQyYjF hZWU5MWZiNGJj\&xzmn=aHR0cHM6Ly9iYW5kdW5na290YS5icHMuZ28uaWQvcHVibGlj YXRpb24vMjAxOC8wOC8xNi9hMjc4MmFINjIwNDJiMWFIZTkxZmI0YmMva290YS1iYW 5kdW5nLWRhbGFtLWFuZ2thLTIwMTguaHRtbA\%3D\%3D\&twoadfnoarfeauf=MjAxOS0wN y0xOCAxODo0NTozNQ\%3D\%3D

Daily Social Id. (2018). Laporan DailySocial: Survey Online Travel Agencies (OTA) 2018.

Kotler, P. (2001). Manajemen Pemasaran: Analisis, Perencanaan, Implementasi dan Kontrol. Jakarta: PT. Prehallindo.

Kotler, P. (2007). Manajemen Pemasaran (12th ed.). New Jersey: PT Indeks.

Kotler, P., \& Amstrong, G. (2008). Prinsip Prinsip Pemasaran (Edisi 12 J). Jakarta: Erlangga.

Kotler, P., \& Keller, K. L. (2012). Marketing Management (Global Edi). London: Pearson Education Limited 2012.

Li-ming, A. K., \& Wai, T. B. (2013). Exploring Consumers' Attitudes and Behaviours toward Online Hotel Room Reservations, 3, 6-11. https://doi.org/10.5923/c.economics.201301.02

Liputan 6. (2018). Target 20 Juta Wisman pada 2019, Kemenpar Siapkan 3 Strategi Ciamik. Retrieved from https://www.liputan6.com/lifestyle/read/3853492/target-20-juta-wisman-pada-2019kemenpar-siapkan-3-strategi-ciamik. Diakses pada 6 Agustus 2019.

Pikiran Rakyat. (2018). Okupansi Hotel di Jawa Barat Terus Menurun. Retrieved from https://www.pikiran-rakyat.com/ekonomi/2019/06/18/okupansi-hotel-di-jawa-barat-terusmenurun

Pramudita, A. S. (2018). Formulasi Model Bisnis Hostel di Bandung dengan Pendekatan Value Chain dan Business Model Canvas ( Studi Kasus : Pinisi Backpacker ), II(1), 32-38.

Pramudita, A. S., Yanuar, A., \& Hilman, T. (2019). BUSINESS MODEL FORMULATION FOR ENEWSPAPER IN INDONESIA ( CASE STUDY: PIKIRAN RAKYAT ) FORMULASI MODEL BISNIS SURAT KABAR ELEKTRONIK DI INDONESIA ( STUDI KASUS: PIKIRAN RAKYAT ), 20(1), 15-31.

Ratnawati, A. T. (2015). Buah Lokal di Kota Semarang, (66), 229-236. 